\title{
The Paradox and Dynamic Betweem Sustainable Development and Corporate Performance
}

\author{
Óliver Silva Costa Barreto ${ }^{1 *}$, Marcelo Santana Pinheiro ${ }^{1}$, Luiz Marcelo Fonseca Soares ${ }^{1}$, Robson Rosario Junior ${ }^{1}$, \\ Marcio Hideki Maruta ${ }^{1}$, Renelson Sampaio ${ }^{1}$, Thiago Barros Murari ${ }^{1}$, Bruna Aparecida Souza Machado ${ }^{1}$ \\ ${ }^{1}$ Senai Cimatec University Center; Salvador, Bahia, Brazil
}

\begin{abstract}
This article discusses the false antagonism between sustainable development and corporate performance amalgamated with the search for innovation, intensive use of technologies, and global awareness, during the COVID-19 pandemic scenario and the transformations imposed on society, together with the effects of the necessary insertion of new technologies such as Artificial Intelligence. The study highlights the interaction between elements of a technological revolution that imposes profound changes in society, organizations, and, at the same time, unprecedented health and environmental crisis that put at risk the capacity of human resilience to build the future, and opportunities to reconcile socio-economic advances and sustainability practices.

Keywords: Economic Development. Sustainability. Innovation. Artificial Intelligence. COVID-19.
\end{abstract}

\section{Introduction}

Faced with the enormous challenges related to the protection of the planet and the issues of development, knowledge, and sustainability, some may question whether it is possible to speak of management skills for sustainable development because this seems to be a theme that contradicts the current economic logic and calls into question the commitment to the future. In addition to raising questions about environmental challenges, "sustainable growth" also brings new perspectives on people's relationship with the environment, suggesting other practices based on new concepts of learning and skills training for work.

This article addresses the paradox and the dynamics between sustainable development, corporate performance, and the current capitalist system. It is a great challenge to incorporate sustainability at the heart of organizations, which still maintain the angry economic models based on polluting and non-renewable energy sources. This challenge is aligned with the idea of possible configurations of organizational practices aimed

Received on 15 September 2021; revised 12 October 2021. Address for correspondence: Óliver Silva Costa Barreto. SENAI CIMATEC. Avenida Orlando Gomes, Número 1845 Piatã, Zip Code: 41650-010, Salvador, Bahia, Brazil. E-mail: oliversc.barreto@gmail.com.

J Bioeng. Tech. Appl. Health 2021;4(4):141-146

C 2021 by SENAI CIMATEC. All rights reserved. at "bearable growth". It can improve through new technologies, new skills, and updates in learning models focused on sustainability.

The emergence of the SARS-CoV-2 coronavirus and the rapid spread, mutation, and lethality of the virus has forced a context of abrupt changes in the way of life in today's society. With the global synergy to fight the pandemic, the emergence of new technologies, fostering innovation, reducing bureaucracy in various means of communication and connectivity, disseminating knowledge, and adapting to a new way of life, society is experiencing an unprecedented moment of inevitable transitions.

The current crisis has intensified the urgency for effective and more than ever immediate solutions. To this end, the intensive use of new technologies and the demand for technological innovations to solve current problems play a central role in today's society. In this panorama, we discussed the current role of Artificial Intelligence (AI).

\section{The Relentless Competition Between Economic and Sustainable Development}

Schumpeter [1] when studying Kondratieff's cycles in detail (Figure 1) and pointing out that periods of economic expansion were leveraged by major innovations in the world economy, which are disruptive forces that allow economic growth and affirming that entrepreneurship is the force propelling economic development, it opposes the 
neoclassical view that defended the economy as something stationary.

Understanding as a determining characteristic of the entrepreneur the search for monopoly profit, arising from the means of production, the entrepreneurial function has played a fundamental role in stimulating economic dynamism using technical ideas and inventions, accessing finance, and transforming these ideas into technological, commercial, and organizational innovations, heating the capitalist economy as a whole $[3,4]$. That said, we emphasize that for corporate development to continue to reach new consumer markets, it is necessary to update, innovate, explore commercial and material resources. And, amid the unregulated balance between the increase in the world population, high consumption of goods, and the insufficiency of policies and practical actions for sustainable products, reverse logistics, and renewable energies, it becomes imperative to remodel how projects have been related to the environment.
Treating sustainability more comprehensively presupposes breaking paradigms in our current society. The broadest treatment of the word refers to the way to conduct the construction of the global society. So, it may guarantee its present and future existence with decent conditions to safeguard the basic needs and further others. There is no way to consider the partial sustainability of one or several countries. It is necessary to consider the impacts of human nature as a whole, rather than individual countries.

An approach much discussed in recent years is that of the Circular Economy, which can be expressed as an economic model aimed at the efficient use of resources supported by their prolonged use, reduction of waste and primary resources, the incentive to closed product cycles, benefits socio-economic, environmentally adapted production processes and systems (Figure 2). It is believed that the circular economy decouples economic

Figure 1. Long waves of innovation.

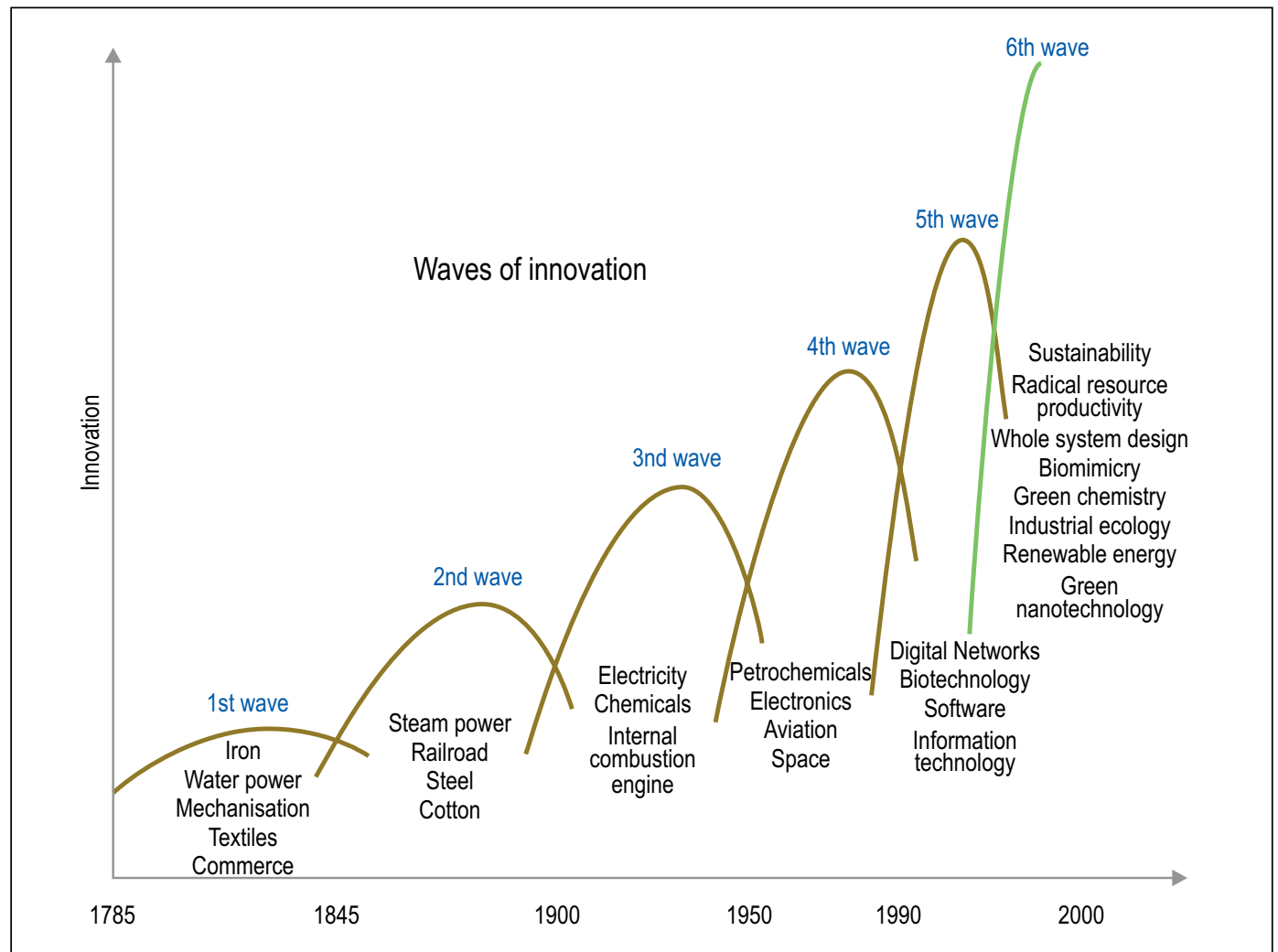

Source: Adapted from Hargroves and Smith [2]. 
Figure 2. Circular economy.

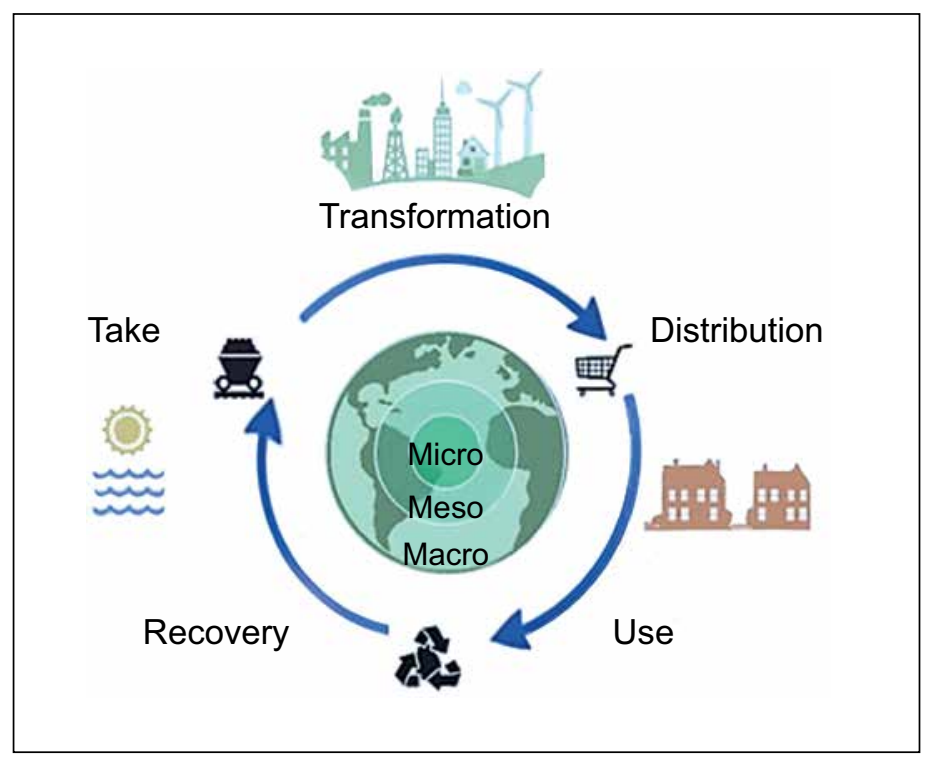

Source: Adapted from Pietro-Sandoval (2018) [7].

growth from the negative consequences of the exploratory use of resources and environmental degradation $[5,6]$.

It is possible to notice that the direction, training, public policies, and sensitivity regarding the allocation of management capacities change due to environmental and social changes. By defining organizational goals and strategies aimed at economic development in parallel with sustainable performance, it is possible to make the organization highly competitive and, even so, engage the entire corporate environment towards a sustainable agenda [8].

\section{$\underline{\text { Post-Covid Social Behavior }}$}

With the arrival of the COVID-19 Pandemic, several companies adhered, almost obligatorily, to the telework or home-office model, aiming at the normal functioning of the operation, accelerating the flexibility of the labor model, which was in a slow growth process [9].

The confinement experience can follow different social paths. Positivist scenarios can touch on the valorization of less materialistic activities and obtaining new technologies developed during COVID-19, there are also possibilities of opposing scenarios that can follow the old normality, virtual materialists, gregarious simplifiers, and online rebels. Figure 3 shows the relationship between sociability and consumption, in a post COVID scenario [10].

The future scenario, related to a long-term sustainable lifestyle, will depend on interactions between governments, corporate commitments, organized civil society activism, barriers, and opportunities, social and environmental imbalances that gave rise to the pandemic itself [10].

Artificial Intelligence and the Paradox of Development and Employability

According to the World Economic Forum, held in September 2020, in 2025, the participation of workers and machines in the labor market was statistically tied, with $53 \%$ of human beings in labor activities, and $47 \%$ of machines. The adoption of digital technologies has been widely applied, such as, for example, Artificial Intelligence (AI), adding competitive differentials to multiple sectors of 
Figure 3. Post COVID scenarios and the relationship between sociability and consumption.

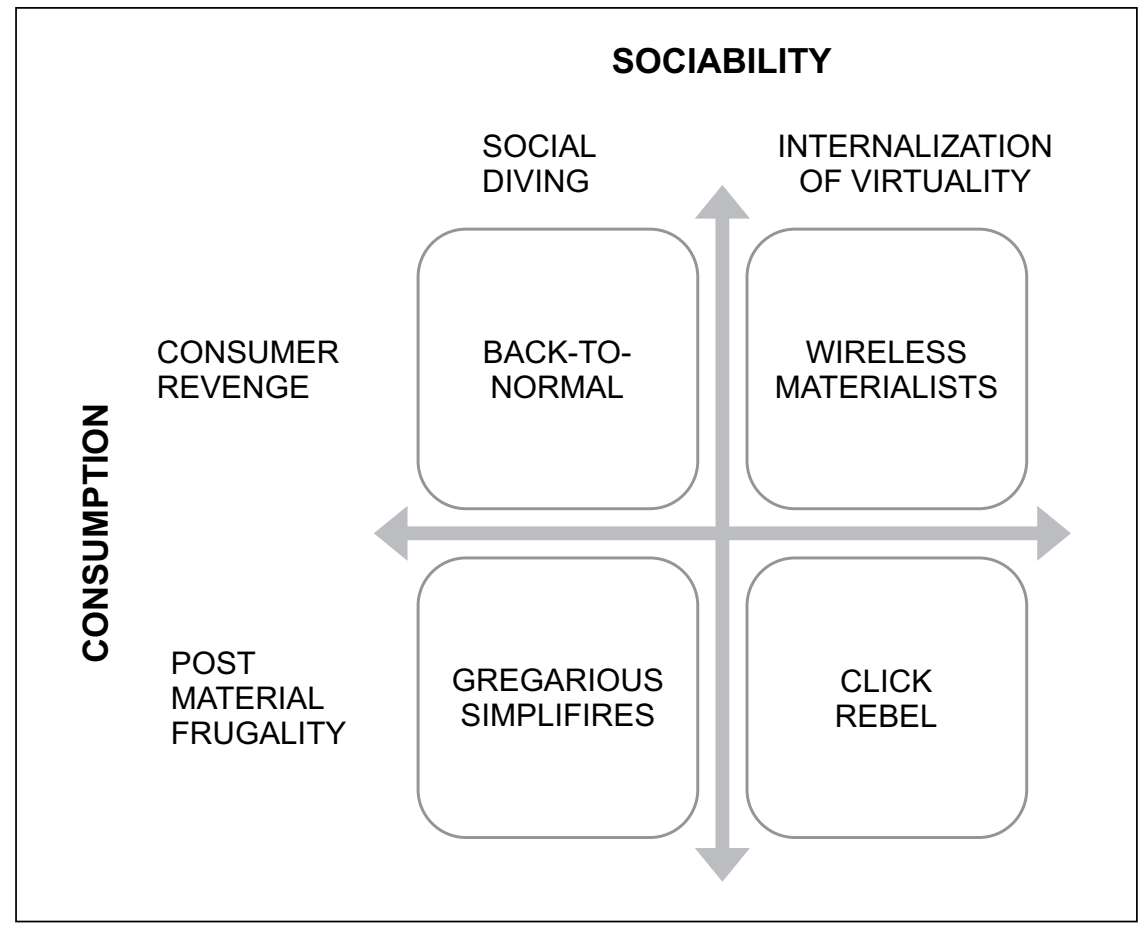

Source: Adapted from Echegaray (2021)[10].

the economy, relevant for the preservation and evolution of business [11].

A new approach to data-based governance is expected for large Brazilian cities. From the race to create new platforms, such as health surveillance and emergency forecasting, artificial intelligence (AI) systems formulate substantiated political evidence inferred through the handling of big data and other sources of information available to governments. Thus, we expected that learning with AI would expand the universalization of government actions. [12].

The COVID-19 scenario reveals inequality in access to digital capital, a mirror of structural inequalities in Brazil. During this period, there will have strong creation and generation of information using technologies, but there is no expectation that this knowledge and potential can reach the entire population. Such issues bring up the risk of reproducing and perpetuating inequalities in the highly technological environments of the future, real and not to be underestimated.
Marginalized groups survive in a complex matrix of vulnerabilities, ranging from economic, social, and legal dimensions to cultural, digital, and political dimensions [12].

\section{Materials and Methods}

The research methodology applied in this article has an observational purpose, aiming to explore modern content based on social and economic sciences. Three aspects related to changes in human relations and the scenario of sustainable development after COVID-19 are analyzed. Furthermore, regarding the nature of the research, it is classified as applied and its approach is qualitative, allowing analysis of specific characteristics in each circumstantial context [13].

This research has an exploratory character, analyzing and updating concepts in a specific context and exploring a current panorama through bibliographic review. 
Concerning technical procedures, the methodology of this article uses bibliographic and documentary research. In this context, scientific publications, articles, and documents from private organizations were used as the basis for the analysis presented in this article.

\section{Results and Discussion}

All the effects perceived by the deceleration of human exploratory activities in the biosphere also called "blessing in disguise" must be analyzed and considered so that it can serve as a guide for a new model of human development that remodels issues of corporate development in communion with sustainable development, in the broader sense of the expression. The constant reflection on the events resulting from the pandemic is crucial for society to self-assess the impacts it has brought to the planet and rethink the possible measures that should be taken within this new capitalist dynamic. Some socio-environmental problems are exposed during the pandemic. The scientific-technological development in the health areas is the most easily perceptible. However, with a little more care, the identification of gaps in the energy, logistics, and material management sectors, which assume new management approaches and the inclusion of increasingly intelligent digital devices (Figure 4).In a "new normal", development must meet the needs of a lifestyle without compromising the capacity of future generations, and, for this, technological innovations and transformations are stimuli for the diffusion and absorption of green technologies, the basis for enabling the challenge in reconciling economic growth and social and environmental well-being. It is a feasible proposal to active influence against the depletion of natural resources and environmental degradation, at a level more adjusted to the opportunities presented during the COVID-19 pandemic.

Thedigital worldreproduces the businessmodels of the physical economy. Thus, in a new dynamic of cities, the use of new technologies developed in the areas of education, health, and infrastructure will contribute to participation and collaboration by citizens, in addition to the possibility of improving public transparency. Thus, there must be an impact on the sustainable development of cities and the potentializing innovation benefits for people. The dynamic after COVID-19, in a perspective of more frugal consumption, signals more and more adherence to the circular economy, with the expectation of developing technologies capable of improving the efficiency of manufactures and use of resources, renewable and recyclable products with

Figure 4. Digitalization of environmental impacts.

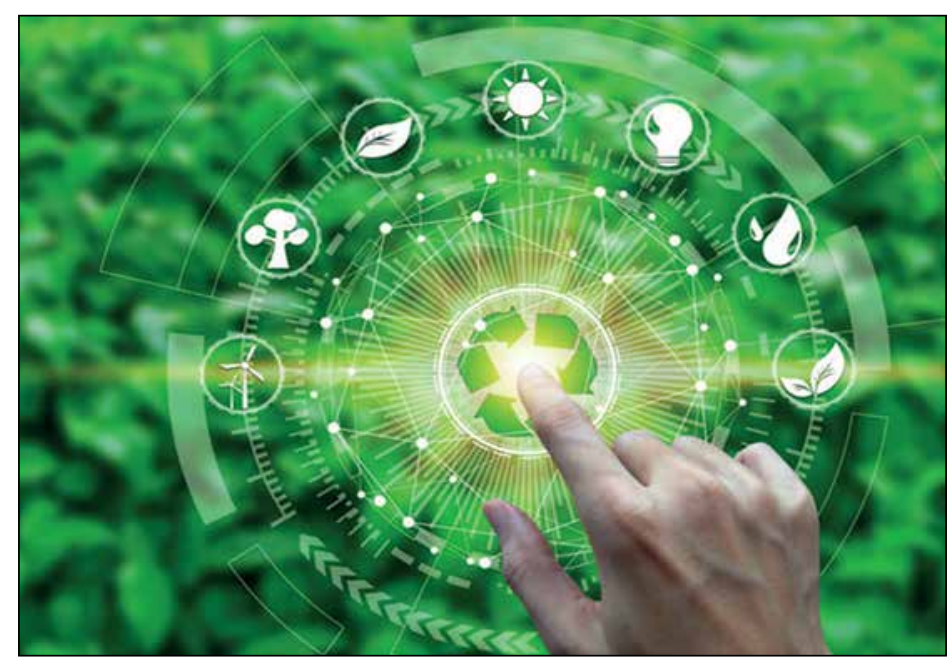

Source: Adapted from Tigre 2014 [4]. 
carbon capture solutions. There is an opportunity for the lessons learned from the collaboration and sharing of information in research, which provided the world with the development of new knowledge and means to support the period of isolation, to be the great technological lever for the union of various branches of the economy, establishing partnerships for the development of innovation and technology, deconstructing the paradox of individualities between nations and companies.

\section{Conclusion}

Through this study, it was possible to respond to existing relationships and highlight that we are experiencingatechnologicalrevolutionthatimposes profound changes that put at risk our capacity for the humanitarian organization to build a more balanced future with sustainable development. Human-machine collaboration and emerging technologies in this country are essential to ensure ethical, creative, and responsible use of AI. It is possible to develop it to support human potential in challenges such as the fight against the coronavirus from a data platform, diagnosis, discovery of new treatments, identification of serious diseases, or monitoring environmental legislation.

It is suggested that the outcome depends on how we will use this knowledge and our capacity for global cooperation towards community goals. Based on effective global cooperation, we will have the opportunity to reconcile social-economic advances and sustainability practices with the recovery of the environment.

\section{References}

1. Bögenhold D. Schumpeter, creative destruction and entrepreneurship. In: World encyclopedia of entrepreneurship. Edward Elgar Publishing, 2021.

2. Hargroves K, Smith M. The natural advantage of nations: business opportunities, innovation, and governance in the 21 st century. The Natural Edge Project, Earthscan: London, 2005.

3. Malerba F, Mckelvey M. Knowledge-intensive innovative entrepreneurship integrating Schumpeter, evolutionary economics, and innovation systems. Small Business Economics 2020;(54)2:503-522.

4. Tigre PB. Gestão da Inovação: a economia da tecnologia no Brasil - 2ª Edição, Rio de Janeiro: Elsevier, 2014.

5. Morseletto P. Targets for a circular economy. Resources, Conservation and Recycling 2020;153:104553.

6. Hofmann F. Circular business models: Business approach as driver or obstructer of sustainability transitions? Journal of Cleaner Production 2019;224:361-374.

7. Prieto-Sandoval V, Jaca C, Ormazabal M. Towards a consensus on the circular economy. Journal of cleaner production 2018;179:605-615.

8. Borges LO, Yamamoto $\mathrm{OH}$. O mundo do trabalho. Psicologia: organizações e trabalho no Brasil 2004;2.

9. Ferreira FFVM, et al. Internet access in the New Brazilian Normal: A basic need for access to income, health, and education. Journal of Bioengineering and Technology Applied to Health 2020;(3)3:298-304.

10. Echegaray F, et al. Sustainable lifestyles after COVID-19. Routledge, 2021.

11. Lamb LC. O futuro do trabalho pós-pandemia de COVID-19: Reflexões sobre os impactos da Inteligência Artificial, ciência educação. Available at: $<$ https://metricas.usp.br/wp-content/uploads/2020/07/ M\%C3\%A9tricasUSP-final09Jul2020-LAMB.LC_. pdf $>$. Access by 05 Aug, 2021.

12. Magalhães LG. A pandemia e a nova ordem sociodigital no sul global: O caso de São Paulo. COVID-19 from the Margins 2021:129.

13. Gil AC. Métodos e técnicas de pesquisa social. 6. ed. Editora Atlas SA, 2008. 